\title{
BMJ Open The development of an online intervention (Care Assist) to support male caregivers of women with breast cancer: a protocol for a mixed methods study
}

\author{
Janelle V Levesque, ${ }^{1,2,3}$ Martha Gerges, ${ }^{1,2}$ Afaf Girgis ${ }^{1,2}$
}

To cite: Levesque JV, Gerges M, Girgis A. The development of an online intervention (Care Assist) to support male caregivers of women with breast cancer: a protocol for a mixed methods study. BMJ Open 2018;8:e019530. doi:10.1136/ bmjopen-2017-019530

- Prepublication history for this paper is available online. To view these files, please visit the journal online (http://dx.doi org/10.1136/bmjopen-2017019530).

Received 8 September 2017 Revised 8 December 2017 Accepted 16 January 2018
Check for updates

${ }^{1}$ Psycho-Oncology Research Group, Centre for Oncology Education and Research Translation (CONCERT), Ingham Institute for Applied Medical Research, Liverpool, New South Wales, Australia

${ }^{2}$ South Western Sydney Clinical School, The University of New South Wales, Liverpool, New South Wales, Australia ${ }^{3}$ School of Psychological Sciences, Faculty of Medicine, Nursing and Health Sciences, Monash University, Clayton, Victoria, Australia

Correspondence to Professor Afaf Girgis; afaf.girgis@unsw.edu.au

\section{ABSTRACT}

Introduction It is projected that 17730 women will be diagnosed with breast cancer in Australia in 2017, with 3114 of these predicted to be fatal. Caregiving for a person with cancer can significantly impact caregivers' physical and mental health. Many caregivers feel ill-prepared for this role, especially when care involves complex medical needs accompanied by the psychological challenges experienced following a cancer diagnosis.

Methods and analysis This study employs a convergent, parallel, mixed methods design combining an online survey with an optional interview. Eligible, consenting participants will be invited to participate in a survey to examine (1) participants' unmet needs, (2) challenges experienced throughout the cancer journey, (3) perceived self-efficacy to determine participants' level of confidence in undertaking caregiver tasks, (4) views regarding suitable content to include in a caregiver training intervention, (5) preferred method of intervention delivery (ie, website, smartphone application and/or interactive video), and (6) preferences for the timing of delivery of the intervention content (ie, ability to choose a module, access to the entire content or have a set order in which they receive the information). Caregivers will be eligible to participate if they (1) are male, (2) have previously cared for or are currently caring for a woman with breast cancer, (3) are aged over 18 years, and (4) do not currently suffer from a cognitive impairment or mental health condition (ie depression, anxiety). Data analysis will include examination of differences in psychological outcomes and needs based on demographic variables, and mediation analysis to explore whether self-efficacy mediates the relationship between challenges, unmet needs and distress. Qualitative data will be analysed using thematic analysis.

Ethics and dissemination The study was reviewed and approved by two human research ethics committees within Australia. We anticipate two to three publications may be developed from the study.

\section{INTRODUCTION}

In the past 20 years, there has been a significant shift towards the provision of cancer care through ambulatory treatment centres. For
Strengths and limitations of this study

- The study uses a mixed methods design. Through the combination of quantitative and qualitative approaches, complex research questions can be explored.

- Inclusion of qualitative interviews allows for potentially confounding variables (eg, profession, family members, socioeconomic status) to be explored without including them in quantitative component, hence avoiding reducing the statistical power of the study.

- Ability to seek the views of caregivers throughout Australia, rather than only our local community, as recruitment partners have a relationship with caregivers Australia-wide.

- Content developed for the Care Assist intervention will need a phase II study exploring the views of caregivers on the developed intervention.

- The Cancer Related Challenges Scale is a relatively new measure with limited information currently available regarding psychometric properties.

example, in Australia, cancer care is primarily delivered through outpatient clinics, and in 2015-2016, 78\% of cancer care in Australian hospitals was conducted in same-day clinics. ${ }^{1}$ This change in care delivery results in the transfer of care to informal caregivers, accompanied by increasing complexity of the tasks such caregivers are required to perform. ${ }^{23} \mathrm{An}$ informal caregiver is any person who provides assistance to another person without training and economic reimbursement for the care they provide. ${ }^{4}$ In Australia, it is estimated that informal caregivers save the federal budget $\$ 40.9$ billion, highlighting the economic value of the role that they provide. ${ }^{5}$

Caregiving has a significant impact on caregivers. However, caregiving comes at a cost for many, ${ }^{6}$ with some caregivers reporting high levels of anxiety and depression, ${ }^{7-9}$ burden 
and unmet needs, ${ }^{810-12}$ declining physical well-being, ${ }^{13} 14$ and significant financial burden. ${ }^{1516}$ Furthermore, there is evidence to suggest that some caregivers do not recover after a period of initial adjustment, creating an 'at-risk' group of caregivers. ${ }^{8}{ }^{17}$ In light of this evidence, some argue that family caregivers should be considered a 'co-user' or 'co-client' of cancer services. ${ }^{18}$ However, in reality, most caregivers are not the recipient of care in relation to their caregiving role ${ }^{1920}$ and are often considered by healthcare providers as being outside their scope of responsibility, despite growing recognition of their unmet needs. ${ }^{21}$

There is also evidence to suggest that caregivers' physical and mental well-being may influence patient status. For example, a meta-analysis conducted by Hodges $e t \mathrm{al}^{22}$ found that there is a positive correlation between patient and caregiver psychological distress. Self-efficacy, an individual's belief in the ability to succeed in situations and accomplish tasks, ${ }^{23}$ has the potential to affect caregiver outcomes and positively impact on patients. Keefe et $a l^{24}$ found that high self-efficacy for pain management tasks in caregivers was linked to increased patient energy and time spent out of bed, and reduced patients' sense of feeling ill. Other studies have also shown beneficial outcomes for patients when their caregivers have received support, with improvements in patient depression ${ }^{25}$ and hopelessness, ${ }^{26}$ enhanced symptom management, ${ }^{27}$ and reduced symptom severity/intensity. ${ }^{28}{ }^{29}$ Therefore, by supporting caregivers and improving their well-being and self-efficacy, there is the potential to enhance quality of life for patients with cancer.

Male caregivers of women with breast cancer continue to experience heightened levels of psychological stress even after treatment ${ }^{30}$ (ie, surgery) has been undertaken by their loved one, lasting anywhere between 3 and 12 months, ${ }^{3031}$ and this is directly related to their feelings and role as a caregiver. ${ }^{30}{ }^{32}$ Similarly, a study conducted by Duggleby $e t a l^{1}$ found that male spousal caregivers have altered quality of life, which is positively influenced by hope and negatively influenced by guilt and method of coping with transition periods. ${ }^{31}$ Coping strategies used by male caregivers include gender-specific attitudes, which were in line with feelings of masculinity, such as focusing on the task at hand or keeping stress to themselves. ${ }^{33}$

Given the high burden associated with being a caregiver, as well as the potential benefits to both caregivers and patients if caregivers are appropriately supported in their role, there is an imperative to consider whether available supports are sufficient and, if not, to develop additional support for caregivers. Support groups can be of assistance to some caregivers. ${ }^{810-12}$ However, there is a paucity of such groups specifically for male partners of women diagnosed with breast cancer, and many caregivers do not have the time to attend such groups. ${ }^{34} 35$ Caregivers may also require support to undertake the more practical tasks of caregiving. For example, research has consistently found that cancer caregivers have insufficient knowledge and skills relating to caregiving tasks (eg, symptom management), and experience communication barriers and lack of emotional support. ${ }^{105-38}$ Most caregivers indicate that they need some level of support, ${ }^{35}$ and identify education, such as caregiver training, as an avenue to address their needs. ${ }^{35} 39$ Two recent reviews ${ }^{40} 41$ undertaken in caregiver training interventions in the cancer context suggest that caregiver training significantly improves caregiver burden, quality of life and self-efficacy, including improved emotional support gained from interventions. $^{4041}$

Notably, Ferrell and Wittenberg ${ }^{40}$ concluded that since 2010 there had been an increase in the number of caregiver interventions using technology and a self-directed format. A recent review of online interventions for family caregivers examined 17 studies, finding positive changes in levels of depression, anxiety and stress/distress, knowledge, bonding, and reduced anger-hostility were achieved through such programmes. ${ }^{42}$ However, the results were not unequivocal, with numerous null findings reported and variable quality of the research being reported. ${ }^{42}$ For cancer caregivers, Kaltenbaugh et $a t^{33}$ reviewed web-based intervention and concluded that such interventions may reduce caregiver burden, negative mood and cancer-specific distress, while increasing quality of life, emotional functioning, bonding and social support. Notably, the six studies in this review were rated as weak in terms of reporting quality and were primarily based on majority of female samples. ${ }^{43}$ It may therefore be tentatively concluded that online caregiver interventions have potential to improve outcomes for caregivers; however, to date little is known about how such interventions may aid men who care for women with breast cancer. ${ }^{44-46}$

Self-efficacy is a potential avenue that may enhance caregiver outcomes. Bandura ${ }^{47}$ conceptualised self-efficacy as the person's view of their ability to perform confidently and capably in a particular situation. In the context of caregiving, a person with high self-efficacy will believe themselves to be able to perform the required tasks, and therefore is more likely to be successful in such tasks and less likely to experience distress or burnout. ${ }^{48}$ Higher levels of caregiver self-efficacy are associated with higher quality of life, ${ }^{49}$ and lower anxiety, ${ }^{50}{ }^{51}$ caregiver strain and psychological distress. ${ }^{52}$ Importantly, self-efficacy is a variable trait that is influenced by the context, task and individual's mood, and therefore may be modifiable through intervention. ${ }^{53}$ While few studies have examined self-efficacy as the focus of caregiver intervention, available evidence suggests that caregiver training interventions can successfully improve self-efficacy in informal caregivers. ${ }^{4454}$ Importantly, recent work by Havyer et a $\tilde{l}^{5}$ has demonstrated that the odds of caregivers having low self-efficacy are significantly higher among caregivers who feel inadequately trained to take on care-related duties. From a broader societal view, evidence suggests that caregivers with high levels of self-efficacy and lower levels of stress are able to more independently support the patients they care for, and achieve better patient outcomes in terms of symptom management and 
psychological well-being, ${ }^{52}$ which may in turn contribute to reduced demand on healthcare and supportive care services. 5657

From our research with couples affected by cancer, the Coping-Together trial, ${ }^{58} 50 \%$ of partners of patients with breast cancer indicated a preference to receive psychosocial information in an online format such as a website or an app rather than through booklets, DVDs or CDs. Their reasons for preferring websites and apps were that they are easier to access (via computer, tablet or smartphone), they are quicker to access, do not require as much time to use (as opposed to a DVD that required dedicating a set amount of time) and are easily reaccessible. Partners indicated they would be able to refer back to a website or app at any time, and hence they are preferable over having a booklet that you need to have with you. Furthermore, Maxwell ${ }^{59}$ found that self-efficacy mediated the relationship between men using technology-related tools and engagement in health-related activities, suggesting that an online caregiver training may be highly suitable for the target population of male caregivers.

The project aims to address a significant void in support for male caregivers of women with breast cancer, by gathering data to inform the development of a caregiver training intervention for this subgroup of cancer caregivers. The information gathered will include (1) an understanding of the challenges and unmet needs experienced by men caring for a patient with breast cancer; and (2) indepth input from male caregivers of women with breast cancer regarding suitable content and timing of delivery for an online caregiver intervention. We will also examine the role of self-efficacy as a potential mechanism to target in the intervention. The following are the specific hypotheses:

1. that unmet need and number of challenges experienced will predict psychological well-being in men who care for women with breast cancer

2. that self-efficacy will mediate the relationship between number of challenges and psychological well-being

3. that self-efficacy will mediate the relationship between unmet needs and psychological well-being.

\section{METHODS AND ANALYSIS}

The study will employ a mixed methodology design, collecting data relating to caregiver concerns and outcomes, while also gaining insight from participants regarding essential inclusions for a caregiver intervention. While a convergent, parallel, mixed methods design will be used as it allows the researchers to obtain concurrently different forms of data to address a research question, an explanatory approach is being undertaken, where the qualitative data will be used to add depth and greater insight into the quantitative results. ${ }^{60}$ The study uses online surveys and individual phone interviews with male caregivers of women diagnosed with breast cancer.

\section{Participants}

Caregivers will be eligible to participate if they are (1) male, (2) have previously cared or are currently caring for a woman with breast cancer (in the capacity of being a relative-such as brother, father, son, uncle, cousin, nephew-spouse or friend of that patient), (3) aged 18 years or older, and (4) are mentally and cognitively able to participate. A minimum sample size of 89 participants is suggested using G*Power: Statistical Power Analyses. ${ }^{61}$ This will allow us to test the hypotheses through multiple regression with two predictor variables, medium effect size $\left(f^{2}=0.15\right), 0.05$ level of statistical significance and $95 \%$ power. $^{61}$ The proposed sample size is the minimum we anticipate achieving and will give us a broad cross section of male caregivers' experiences and needs while also ensuring we can perform the proposed data analysis. All potential participants will be responsible for self-screening and will determine their own eligibility based on questions set up in SurveyMonkey. The survey is designed to automatically exclude respondents who select 'yes' to the question 'Do you currently suffer from a mental health condition (ie, depression, anxiety)?' As the study is designed to explore the challenges experienced throughout the cancer journey, and that such challenges may be present years after diagnosis, no limit has been placed on time since diagnosis as an exclusion criterion.

\section{Recruitment}

The study will employ a convenience sampling strategy with recruitment through two organisations with databases containing members who have previously indicated their willingness to be informed about research opportunities relating to cancer. Specifically, Breast Cancer Network Australia ${ }^{62}$ will contact their members on the Review and Survey Group database and promote the study through social media, and Register $4^{63}$ will contact members whom they deem to be eligible for this study and promote the study through their email newsletter. Data collection is anticipated to take 12 months to ensure the sample size is met, with data collection commencing in January 2017.

\section{Procedure}

Men who respond to the recruitment efforts will follow a link provided in the recruitment message to the online survey. At this point, they will again be presented with the study participant information statement to ensure they are aware of the study details and the contact details of support organisations. Men who consent to take part in the study will then progress to the online survey, which is hosted on SurveyMonkey. The survey is estimated to take 10-20 min for participants to complete.

SurveyMonkey has comprehensive privacy measures set up in order to ensure participant data are protected. Under their privacy policy, we are the sole owners of the data collected using our survey link, and the data are held on secure servers located in the USA. Data can only be accessed by members of the research team who have been 
given the username and password to the SurveyMonkey account. ${ }^{64}$

At the completion of the online survey, participants will be asked if they wished to participate in an optional phone interview to further explore their answers to the survey items. Participants who elect to take part in the interview will be directed to a second survey site, where they will provide their name, contact details, and preferred day and time for interview. Date of birth will be collected in both the online survey and interview consent to allow researchers to match data based on date of birth and date of survey submission, and to examine survey data prior to conducting phone interviews.

Participants who consent to take part in the interview will be contacted by a member of the research team to set a time and date for the interview. Interviews will take approximately 20-30 min and will explore in greater depth participants' challenges, caregiving needs and preferences for supportive intervention materials. All interviews will be recorded and transcribed verbatim.

\section{Measures}

Online survey

As detailed in this section, the online survey will include measures to assess participant demographics, care recipient's breast cancer history, participants' emotional well-being, their cancer-related challenges, self-efficacy and unmet needs, and their perceptions about aspects of the proposed online caregiver training programme, including the content and modes of delivery of such a training programme.

\section{Demographics and breast cancer history}

Demographic data include date of birth, country of birth, language spoken at home, relationship status, level of education, employment status and residential postcode, and relationship to the woman with breast cancer (eg, spouse, sibling, father). Participants will also be asked to report on the stage of cancer, time since diagnosis and type of treatment undertaken by the woman with breast cancer for whom they care (d).

\section{Emotional well-being}

This will be assessed using the Emotion Thermometers (ET) ${ }^{65}$ which are a simple, rapid measure of emotional disorders, including distress, anxiety, depression and anger. Validity of the distress, anxiety and depression components of this tool was achieved using the subscales of the Hospital and Anxiety Depression Scale that correspond to that area, and the depression component of the tool was validated using the Diagnostic and Statistical Manual for Mental Disorders-IV symptom criteria for depression. ${ }^{65}$ Using a $0-10$ rating scale, participants indicate the severity of each emotion over the past week. Individual thermometer scores can be used, or an overall score created by summing all thermometers, with scores above 9 indicating mild problems, above 14 as moderate problems and above 20 as severe emotional problems. ${ }^{66}$
The ET also asks participants to rate their need for help on a scale on 0 (can manage myself) to 10 (desperately). The ET has demonstrated strong sensitivity and validity when assessing distress, anxiety and depression in patients with cancer. ${ }^{65}$ Two additional questions were added to the current study, asking participants to rate the impact of their loved one's breast cancer and whether the caregiver had needed help dealing with the impact of breast cancer.

\section{Cancer-related challenges}

These will be assessed using the Cancer Related Challenge Scale (CRCS), which measures the number of challenges participants faced throughout the cancer experience. ${ }^{67}$ The 39-item CRCS was originally designed for use among patients with cancer and their partners but was adapted for use in the current study to explore cancer-related challenges more fully. The adaption included the addition of two subscales addressing (1) whether the challenge was currently being experienced and (2) whether participants had sought help for such challenges. Participants will respond to each subscale by indicating yes or no, and the number of 'yes' responses within each subscale will be counted to create a subscale score. The current scale is yet to be validated, although psychometric properties are currently being established through its use in this project and through another project which is nearing completion. ${ }^{67}$

\section{Caregiver self-efficacy}

The Communication and Attitudinal Self-Efficacy Scale for Cancer (CASE-Cancer) ${ }^{68}$ was adapted for use with a caregiver population in the current study. The scale consists of 12 items comprising three subscales: (1) understanding and participating in care; (2) maintaining a positive attitude; and (3) seeking and obtaining information. ${ }^{68}$ Items were measured using a 4-point response scale ( $1=$ strongly disagree, $2=$ =slightly disagree, $3=$ =slightly agree, $4=$ strongly agree). Individual items in each of the three 4-item subscales are summed to achieve subscale scores. Higher scores indicate higher self-efficacy for that specific cancer outcome. The CASE-Cancer scale has demonstrated high internal consistency using Cronbach's coefficient alphas $(\alpha=0.76-0.77$ for subscales) and construct validity when used among patient populations. ${ }^{68}$

\section{Caregiver unmet needs}

The Supportive Care Needs Survey-Partners and Caregivers (SCNS-P\&C) ${ }^{69}$ is a 45 -item tool used to measure caregivers' unmet needs across multiple domains, including (1) psychological, (2) health system and information, (3) physical and daily living, (4) patient care and support, and (5) sexuality. ${ }^{69}$ Participants rate items using a 5-point scale ( $1=$ not applicable, $2=$ satisfied, $3=$ low need, $4=$ moderate need, $5=$ high need), with scores of 3-5 indicating varying levels of unmet need. The SCNS-P\&C has been shown to hold psychometrically sound features, including internal consistency (minimum $\alpha=0.70$ ) and construct validity. ${ }^{69}$ Construct validity of the tool was 
achieved using the known-groups approach and internal consistency achieved using the "eigenvalue $<1$ rule, scree plot and parallel analysis..., where items were primarily included in the factor where their loading was the highest (minimum 0.30), ${ }^{69}$

\section{Content and delivery of caregiver training intervention}

Participants will be asked to rate their level of interest in participating in a breast cancer supporters training programme $(0=$ not at all interested, to $10=$ extremelyinterested). Questions also asked about preferred format (eg, static or dynamic website, apps, DVDs), optimal time to receive the intervention (eg, at diagnosis, any time, at commencement of treatment), and whether content should be always available or released in module (eg, one section per week over 4 weeks).

\section{Telephone interviews}

After the online survey, participants will be asked whether they would like to take part in an optional telephone interview. If they indicated yes, participants will be redirected to an additional survey site where they will be presented with an online consent form, confirming their willingness to participate in the interview. After indicating their consent, participants provide their name and preferred contact details so the interview could be arranged. The phone interview is designed to further explore the challenges participants have experienced and discuss their ideas for a male caregiver intervention. An interview guide has been developed to explore two main areas: (1) the experience of caregiving and (2) intervention content. To explore the experience of caring for a woman with breast cancer, participants will be asked about the main challenges faced, how communication and daily routine were impacted, the extent to which caregivers felt informed about their loved one's condition, and whether they had struggled with uncertainty. An example question is: What would you say were the main challenges faced as a result of caring for your wife/sister/mother? To explore potential intervention content and mode of delivery, participants will be asked about their potential interest in a caregiver training/support intervention, what information they believe should be included, the preferred method of intervention delivery and the timing of participating in a supportive care intervention. An example question is: What do you think would be the essential elements for a caregiver training or support package?

Interviews will be conducted by several members of the research team, led by an experienced qualitative researcher (JVL). The interviewers have undergone training in general interviewing techniques and/or have been involved in previous studies involving the interviewing of patients with cancer and their caregivers. Prior to study commencement, a training meeting and mock interviews were conducted to ensure familiarity with the interview schedule. Additionally, the lead researcher (JVL) will review the initial interviews conducted by other team members to provide any required feedback.

\section{Data analysis}

Demographic variables will be examined to determine whether they are indicative of higher challenges, unmet needs or poorer psychological outcomes for male caregivers of women with breast cancer. This will be determined through a number on multivariate analysis of variances (MANOVAs), allowing simultaneous examination of the three dependent variables (distress, challenges and needs) to reduce the risk of type 1 error. To address the first hypothesis, hierarchical multiple regression analyses will be conducted with any demographic items identified as risk factors for distress entered in step 1 , with challenges and unmet needs entered at step 2 . We anticipate the self-efficacy may mediate the relationship between challenges and unmet needs to emotional distress. If this is found to be the case, our goal is to develop a caregiver support programme specifically designed to enhance self-efficacy in male caregivers. Therefore, two mediation analyses will be performed, using the methodology and PROCESS tool developed by Hayes. ${ }^{70}$ Due to multiple analyses being conducted on the data, a Bonferroni correction will be applied to reduce the risk of familywise error. $^{71}$

Qualitative data will be transcribed verbatim in preparation for data analysis. Participants who indicate as part of their consent process that they would like to receive a copy of their transcript will have the opportunity to review the data for accuracy prior to analysis. The qualitative data collected via the interviews will be analysed using thematic analysis (TA). This approach to qualitative data reflects a creative process in which the data and the researcher's interpretative and analytical skills interact in the creation of patterned meanings, of themes, which are drawn from the data. ${ }^{72}$ Using the procedure suggested by Braun $e t a l,{ }^{73}$ the analysis will begin with a reading and rereading of the data set to ensure the researcher is familiar with the data, with points of potential interest noted. After familiarity is established, coding will begin, with codes or labels assigned to elements of the data. Once coding is complete, the creation of themes will be undertaken, by clustering related codes that speak to similar meanings. At this point, potential themes will be checked back to the original data, to ensure that they represent the data in its entirety. The final stage involves defining and naming the themes, culminating in a thematic definition. TA will be conducted by one researcher (JVL) with a proportion of cases reviewed and the coding and theme review processes discussed with a second researcher (MG) as a credibility check. ${ }^{74}$ Direct member checking (ie, participants' review of the data analysis) will not be undertaken as it is anticipated that there will be great diversity on the accounts that will be gathered, and this may create issues regarding members' ability to synthesise data, members' inability to recognise that there is no single objective truth and conflict regarding whose interpretation should be presented if there are disagreements in interpretation. ${ }^{75}$ 
An integration approach ${ }^{76}$ will be undertaken for the combination of the two forms of data. This approach requires the two sets of data to be collected concurrently and then analysed independently. ${ }^{76}$ Once quantitative and qualitative data have been analysed, they will be combined in an attempt to address the central mixed methods research goal of gaining insight into the challenges experienced by male caregivers, and their views on what content is suitable for an intervention to support male caregivers. In this process, the qualitative themes and quantitative results will be compared and complemented with each other, resulting in a summary of the findings. ${ }^{76}$ The integration of the two forms of data will enable the researchers to draw meta-inferences that relate to how the qualitative data provide greater insight to the quantitative conclusions. ${ }^{77}$

\section{Ethical considerations and dissemination}

The study involves a potentially vulnerable group within our community and requires participants to reflect on a distressing time in their life. As such, it is imperative that the study is conducted in a sensitive manner and that participants are provided with access to suitable support services (eg, Lifeline, Cancer Council). Participants were also informed of their right to withdraw from the project or decline to answer questions that elicited distress. The study design also excludes people who have been diagnosed with a mental health condition or other condition that impacts on their cognition (eg, dementia, intellectual disability). This is due to the nature of the study, requiring discussion of potentially upsetting topics, but also that participants will be asked to voice their views on how to develop an online intervention, hence they must have the cognitive capacity to reflect on their experience and express their opinions coherently.

The study findings will greatly enhance our understanding of the experience of breast cancer caregivers including the challenges they face and their unmet needs. As such, we anticipate that at least two to three publications may be developed from the study, including a publication of the qualitative results.

\section{DISCUSSION}

Male caregivers are an under-recognised and under-researched group, ${ }^{33}$ and it is therefore important that studies are conducted to explicitly examine the unmet needs, challenges and psychological outcomes for this group. This study will shed some insight into the experiences of men caring for women with breast cancer, and guide the development of a suitable caregiver training intervention, Care Assist, developed specifically to address the most common challenges of male caregivers. Additionally, by exploring the potential for self-efficacy to explain the association between challenges, unmet needs and emotional problems, this study will clearly examine a potentially modifiable pathway on which to target interventions for male caregivers.
The use of a mixed methods design is a strength of the study. Through the combination of quantitative and qualitative approaches, complex research questions can be explored. ${ }^{78}$ For example, the study will cover a broad snapshot of the types of challenges experienced through the online survey. However, the lived experience of such challenges, the impact they have on participants and the suitability of including such challenges in an intervention can be explored in the qualitative interviews, hence adding a depth of understanding and guiding intervention development in a nuanced manner. Furthermore, should the findings of the qualitative and quantitative elements of the project converge, the validity of the findings, the conclusions drawn and the intervention developed is enhanced. ${ }^{78}$

The results of this project will inform the development of an online self-management intervention to assist male supporters of women with breast cancer, following the four key steps proposed by McKleroy et al. ${ }^{79}$ In brief, the current project will provide the information usually gathered through a needs assessment (step 1); we will develop the intervention content, incorporating ongoing feedback from male supporters to allow iterative modifications as necessary (step 2); we will undertake preliminary adaptation testing to determine the feasibility of the intervention material, including the suitability of content, format and scope of the intervention materials (step 3); and then undertake final intervention refinement through testing of intervention content (step 4).

\section{Limitations}

While the proposed study have several strengths, there are also notable limitations. The CRCS is a relatively new measure with limited information currently available regarding its psychometric properties. We have used this scale in research being undertaken by our group, ${ }^{67}$ and hope that the current study will further contribute to the measure's development. Additionally, the eligibility criteria are relatively broad, with no time frame imposed between time of diagnosis and participation. While this decision was made to ensure that we captured challenges throughout the experience of caring for a woman with breast cancer, we do acknowledge that recall bias may be present. Finally, the content developed for the Care Assist intervention will need a phase II study exploring the views of caregivers on the developed intervention content.

Acknowledgements The authors would like to thank the recruitment partners, Breast Cancer Network Australia (BCNA) and Register4.

Contributors JVL contributed to the study conception and design, attaining the funding to support the project, and preparing documents for ethical approval. She contributed content to the original manuscript and has assisted with revisions. MG contributed to the preparation of documents for ethics approval, including study materials (survey, patient information and so on) to support data collection, managed the liaison with recruitment partners, managed the data collection, and contributed to the preparation and review of the manuscript. AG contributed to the study conception and design, attaining the funding to support the project, and preparation and review of the manuscript.

Funding This work was supported by an Ingham Institute for Applied Medical Research grant. MG and AG are supported by Cancer Institute NSW grants. 
CONCERT is funded by Cancer Institute NSW, with contributions from the University of New South Wales, Western Sydney University, University of Wollongong, Illawarra and Shoalhaven Local Health Districts, and the Ingham Institute for Applied Medical Research.

Competing interests None declared.

\section{Patient consent Obtained.}

Ethics approval The study was reviewed and approved by the Human Research Ethics Committees of South Western Sydney Local Health District (SWSLHD, approval number: HREC/16/LPOOL/34) and Monash University (MUHREC, approval number: 2016-1007).

Provenance and peer review Not commissioned; externally peer reviewed.

Open Access This is an Open Access article distributed in accordance with the Creative Commons Attribution Non Commercial (CC BY-NC 4.0) license, which permits others to distribute, remix, adapt, build upon this work non-commercially, and license their derivative works on different terms, provided the original work is properly cited and the use is non-commercial. See: http://creativecommons.org/ licenses/by-nc/4.0/

(C) Article author(s) (or their employer(s) unless otherwise stated in the text of the article) 2018. All rights reserved. No commercial use is permitted unless otherwise expressly granted.

\section{REFERENCES}

1. Australian Institute of Health and Welfare (AlHW). Australia's hospitals at a glance 2015-16: Australian Institute of Health and Welfare (AlHW), 2017.

2. O'Mara A. Who's taking care of the caregiver? J Clin Oncol 2005;23:6820-1.

3. Lambert SD, Levesque JV, Girgis A. The impact of cancer and chronic conditions on caregivers and family members. Koczwara B, ed. Cancer and chronic conditions. Singapore: Springer, 2016:159-202.

4. Carretero S, Garcés J, Ródenas F, et al. The informal caregiver's burden of dependent people: theory and empirical review. Arch Gerontol Geriatr 2009;49:74-9.

5. Access Economics. The economic value of informal care in 2010 : report for carers Australia. Carers Australia, 2010.

6. Girgis A, Lambert S, Johnson C, et al. Physical, psychosocial, relationship, and economic burden of caring for people with cancer: a review. J Oncol Pract 2013;9:197-202.

7. Braun M, Mikulincer M, Rydall A, et al. Hidden morbidity in cancer: spouse caregivers. J Clin Oncol 2007;25:4829-34.

8. Girgis A, Lambert SD, McElduff P, et al. Some things change, some things stay the same: a longitudinal analysis of cancer caregivers' unmet supportive care needs. Psychooncology 2013;22:1557-64.

9. Mazzotti E, Sebastiani C, Antonini Cappellini GC, et al. Predictors of mood disorders in cancer patients' caregivers. Support Care Cancer 2013;21:643-7.

10. Molassiotis A, Wilson B, Blair S, et al. Unmet supportive care needs, psychological well-being and quality of life in patients living with multiple myeloma and their partners. Psychooncology 2011;20:88-97.

11. Kim Y, Schulz R. Family caregivers' strains: comparative analysis of cancer caregiving with dementia, diabetes, and frail elderly caregiving. J Aging Health 2008;20:483-503.

12. Grant M, Sun V, Fujinami R, et al. Family caregiver burden, skills preparedness, and quality of life in non-small cell lung cancer. Oncol Nurs Forum 2013;40:337-46.

13. Stenberg U, Ruland CM, Miaskowski C. Review of the literature on the effects of caring for a patient with cancer. Psychooncology 2010;19:1013-25.

14. Cummins RA, HUghes J, Tomyn A, et al. The wellbeing of australians: carer health and wellbeing, 2007.

15. Adelman RD, Tmanova LL, Delgado D, et al. Caregiver burden: clinical review. JAMA 2014;311:1052-60.

16. Girgis A, Lambert SD. The cost of informal caregiving in cancer care. Cancer Forum, 2017.

17. Lambert SD, Jones BL, Girgis A, et al. Distressed partners and caregivers do not recover easily: adjustment trajectories among partners and caregivers of cancer survivors. Ann Behav Med 2012;44:225-35.

18. Thomas C, Morris SM. Informal carers in cancer contexts. Eur J Cancer Care 2002;11:178-82.
19. Mitchell G, Girgis A, Jiwa M, et al. A GP caregiver needs toolkit versus usual care in the management of the needs of caregivers of patients with advanced cancer: a randomized controlled trial. Trials 2010;11:115.

20. Burridge LH, Mitchell GK, Jiwa M, et al. Consultation etiquette in general practice: a qualitative study of what makes it different for lay cancer caregivers. BMC Fam Pract 2011;12:110.

21. Regan T, Levesque JV, Lambert SD, et al. A qualitative investigation of health care professionals', patients' and partners' views on psychosocial issues and related interventions for couples coping with cancer. PLoS One 2015;10:e0133837.

22. Hodges LJ, Humphris GM, Macfarlane G. A meta-analytic investigation of the relationship between the psychological distress of cancer patients and their carers. Soc Sci Med 2005;60:1-12.

23. Bandura A. Self-efficacy: toward a unifying theory of behavioral change. Advances in Behaviour Research and Therapy 1978;1:139-61.

24. Keefe FJ, Ahles TA, Porter LS, et al. The self-efficacy of family caregivers for helping cancer patients manage pain at end-of-life. Pain 2003:103(1-2):157-62.

25. Blanchard CG, Toseland RW, McCallion P. The effects of a problemsolving intervention with spouses of cancer patients. J Psychosoc Oncol 1996;14:1-21.

26. Northouse L, Kershaw T, Mood D, et al. Effects of a family intervention on the quality of life of women with recurrent breast cancer and their family caregivers. Psychooncology 2005;14:478-91.

27. Ferrell BR, Grant $M$, Chan J, et al. The impact of cancer pain education on family caregivers of elderly patients. Oncol Nurs Forum 1995;22:1211-8.

28. Given B, Given CW, Sikorskii A, et al. The impact of providing symptom management assistance on caregiver reaction: results of a randomized trial. J Pain Symptom Manage 2006;32:433-43.

29. McMillan SC, Small BJ. Using the COPE intervention for family caregivers to improve symptoms of hospice homecare patients: a clinical trial. Oncol Nurs Forum 2007;34:313-21.

30. Chronopoulou K, Sakkas D, Damigos D. Caregiving burden and psychological distress of breast cancer patients' husbands after mastectomy. International Journal of Caring Sciences 2016;9:909-13.

31. Duggleby W, Thomas J, Montford K, et al. Transitions of male partners of women with breast cancer: hope, guilt, and quality of life. Oncol Nurs Forum 2015;42:134

32. Cairo Notari S, Favez N, Notari L, et al. The caregiver burden in male romantic partners of women with non-metastatic breast cancer: The protective role of couple satisfaction. J Health Psychol 2017;22:1668-77.

33. Lopez V, Copp G, Molassiotis A. Male caregivers of patients with breast and gynecologic cancer: experiences from caring for their spouses and partners. Cancer Nurs 2012;35:402.

34. Gerges M, Levesque J, Girgis A. Challenges, supportive care needs and coping strategies of Chinese women with breast cancer. The VCCC survivorship conference and the victorian psycho-oncology research conference. Melbourne Victoria, 2016.

35. Jansma FF, Schure LM, de Jong BM, Meyboom de Jong B. Support requirements for caregivers of patients with palliative cancer. Patient Educ Couns 2005;58:182-6.

36. Oldham L, Kristjanson LJ. Development of a pain management programme for family carers of advanced cancer patients. Int $J$ Palliat Nurs 2004;10:91-9.

37. Schumacher KL, Koresawa S, West C, et al. Putting cancer pain management regimens into practice at home. J Pain Symptom Manage 2002;23:369-82.

38. McCarthy B. Family members of patients with cancer: what they know, how they know and what they want to know. Eur J Oncol Nurs 2011:15:428-41.

39. Bialon LN, Coke S. A study on caregiver burden: stressors, challenges, and possible solutions. Am J Hosp Palliat Care 2012;29:210-8.

40. Ferrell $\mathrm{B}$, Wittenberg $\mathrm{E}$. A review of family caregiving intervention trials in oncology. CA Cancer J Clin 2017:67:318-25.

41. Northouse LL, Katapodi MC, Song L, et al. Interventions with family caregivers of cancer patients: meta-analysis of randomized trials. $C A$ Cancer J Clin 2010;60:317-39.

42. Ploeg J, Markle-Reid M, Valaitis R, et al. Web-based interventions to improve mental health, general caregiving outcomes, and general health for informal caregivers of adults with chronic conditions living in the community: rapid evidence review. J Med Internet Res 2017;19:e263.

43. Kaltenbaugh DJ, Klem ML, Hu L, et al. Using Web-based interventions to support caregivers of patients with cancer: a systematic review. Oncol Nurs Forum 2015;42:156-64. 
44. Hendrix CC, Landerman R, Abernethy AP. Effects of an individualized caregiver training intervention on self-efficacy of cancer caregivers. West J Nurs Res 2013;35:590-610.

45. Porter LS, Keefe FJ, Garst J, et al. Caregiver-assisted coping skills training for lung cancer: results of a randomized clinical trial. J Pain Symptom Manage 2011;41:1-13.

46. Lewis FM, Cochrane BB, Fletcher KA, et al. Helping Her Heal: a pilot study of an educational counseling intervention for spouses of women with breast cancer. Psychooncology 2008;17:131-7.

47. Bandura A. Self-efficacy: the exercise of control. New York: W.H: Freeman, 1997.

48. Merluzzi TV, Philip EJ, Vachon DO, et al. Assessment of self-efficacy for caregiving: the critical role of self-care in caregiver stress and burden. Palliat Support Care 2011;9:15-24.

49. Duggleby W, Doell H, Cooper D, et al. The quality of life of male spouses of women with breast cancer: hope, self-efficacy, and perceptions of guilt. Cancer Nurs 2014;37:E28-E35.

50. Mystakidou K, Parpa E, Panagiotou I, et al. Caregivers' anxiety and self-efficacy in palliative care. Eur J Cancer Care 2013;22:188-95.

51. Ugalde A, Krishnasamy M, Schofield P. The relationship between self-efficacy and anxiety and general distress in caregivers of people with advanced cancer. J Palliat Med 2014;17:939.

52. Porter LS, Keefe FJ, Garst J, et al. Self-efficacy for managing pain, symptoms, and function in patients with lung cancer and their informal caregivers: associations with symptoms and distress. Pain 2008;137:306-15.

53. Crellin NE, Orrell M, McDermott O, et al. Self-efficacy and healthrelated quality of life in family carers of people with dementia: a systematic review. Aging Ment Health 2014.18.

54. Hendrix CC, Abernethy A, Sloane R, et al. A pilot study on the influence of an individualized and experiential training on cancer caregiver's self-efficacy in home care and symptom management. Home Healthc Nurse 2009;27:271-8.

55. Havyer RD, van Ryn M, Wilson PM, et al. The effect of routine training on the self-efficacy of informal caregivers of colorectal cancer patients. Support Care Cancer 2017;25:1071-7.

56. Rabow M, Kvale E, Barbour L, et al. Moving upstream: a review of the evidence of the impact of outpatient palliative care. $J$ Palliat Med 2013;16:1540-9.

57. Empeño J, Raming NT, Irwin SA, et al. The hospice caregiver support project: providing support to reduce caregiver stress. J Palliat Med 2011;14:593-7.

58. Lambert SD, Girgis A, McElduff P, et al. A parallel-group, randomised controlled trial of a multimedia, self-directed, coping skills training intervention for patients with cancer and their partners: design and rationale. BMJ Open 2013;3:e003337-12.

59. Maxwell K. In: Cortner D, Bowden R, Gerrior S, eds. Technology as a health intervention and the self-efficacy of men. ProQuest Dissertations Publishing, 2015.

60. Halcomb E, Hickman L. Mixed methods research. Nurs Stand 2015;29:41-7.
61. Buchner A, Erdfelder E, Faul F, et al. G*Power: statistical power analyses for windows and mac. $2014 \mathrm{http}: / / w w w . g p o w e r . h h u . d e / e n$. html

62. BCNA. Who are we: breast cancer network australia. $2017 \mathrm{https}: / /$ www.bcna.org.au/about-us/who-we-are/2017

63. What is Register4. National breast cancer foundation. $2017 \mathrm{http}: / /$ www.register4.org.au/public/aboutus/what-is-register42017

64. SurveyMonkey. Security statement United States. $2017 \mathrm{https} / / / \mathrm{www}$. surveymonkey.com/mp/policy/security/

65. Mitchell AJ, Baker-Glenn EA, Granger L, et al. Can the distress thermometer be improved by additional mood domains? Part I. initial validation of the emotion thermometers tool. Psychooncology 2010;19:125-33.

66. Mitchell A. Emotion thermometers tool leicester. $2013 \mathrm{http} / / / \mathrm{www}$. psycho-oncology.info/ET.htm

67. Lambert SD, Girgis A, Turner J, et al. A pilot randomized controlled trial of the feasibility of a self-directed coping skills intervention for couples facing prostate cancer: rationale and design. Health Qual Life Outcomes 2012;10:119.

68. Wolf MS, Chang CH, Davis T, et al. Development and validation of the communication and attitudinal self-efficacy scale for cancer (CASE-cancer). Patient Educ Couns 2005;57:333-41.

69. Girgis A, Lambert S, Lecathelinais C. The supportive care needs survey for partners and caregivers of cancer survivors: development and psychometric evaluation. Psychooncology 2011;20:387-93.

70. Hayes AF. Introduction to mediation, moderation, and conditional process analysis: a regression-based approach. New York: The Guilford Press, 2013.

71. Field A. Discovering statistics using IBM SPSS statistics. Discovering statistics using SPSS. 4th ed. London: Sage Publications Ltd, 2013.

72. Braun V, Clarke V. Thematic analysis. American Psychological Association, 2012.

73. Braun V, Clark V, Terry G. Thematic analysis. In: Rohleder P, Lyons A, eds. Qualitative research in clinical and health psychology. Basingstoke: Palgrave MacMillan, 2014:95-113.

74. Thomas E, Magilvy JK. Qualitative rigor or research validity in qualitative research. J Spec Pediatr Nurs 2011;16:151-5.

75. Angen MJ. Evaluating interpretive inquiry: reviewing the validity debate and opening the dialogue. Qual Health Res 2000;10:378-95.

76. Zhang W, Creswell J. The use of "mixing" procedure of mixed methods in health services research. Med Care 2013;51:e51-e57.

77. Creswell JW, Plano-Clark VL. Designing and conducting mixed methods research. 2nd ed. Nebraska USA: SAGE Publications, Inc, 2011.

78. Lund T. Combining qualitative and quantitative approaches: some arguments for mixed methods research. Scand J Educ Res 2012;56:155-65.

79. McKleroy VS, Galbraith JS, Cummings B, et al. Adapting evidencebased behavioral interventions for new settings and target populations. AIDS Educ Prev 2006;18:59-73. 